\title{
Article
}

\section{Developing content to promote desistance in men who have committed intimate partner violence in same-sex relationships}

Morris, Jason, Gibbs, Charlotte, Jonah, Lara, Bloomfield, Sinead, Weatherstone, Paul and Ireland, Jane Louise

Available at http://clok.uclan.ac.uk/29467/

Morris, Jason, Gibbs, Charlotte, Jonah, Lara, Bloomfield, Sinead, Weatherstone, Paul and Ireland, Jane Louise ORCID: 0000-0002-5117-5930 (2019)

Developing content to promote desistance in men who have committed intimate partner violence in same-sex relationships. European Journal of Probation, 11 (2). pp. 96-113.

It is advisable to refer to the publisher's version if you intend to cite from the work. $10.1177 \% 2 F 2066220319871454$

For more information about UCLan's research in this area go to http://www.uclan.ac.uk/researchgroups/ and search for <name of research Group>.

For information about Research generally at UCLan please go to http://www.uclan.ac.uk/research/

All outputs in CLoK are protected by Intellectual Property Rights law, including Copyright law. Copyright, IPR and Moral Rights for the works on this site are retained by the individual authors and/or other copyright owners. Terms and conditions for use of this material are defined in the policies page. 


\title{
Developing Content to Promote Desistance in Men Who Have Used Violence Against
} a Male Intimate Partner

\author{
J. Morris ${ }^{1}$, C. A. Gibbs, O. T. Jonah, S. Bloomfield, P. H. Weatherstone, and J. L. Ireland*
}

\author{
HM Prison and Probation Service, UK
}

*School of Psychology, University of Central Lancashire. Preston, PR1 2HE, UK

\begin{abstract}
Jason Morris is a Chartered and Forensic psychologist with 18 years of experience working in Her Majesty's Prisons and Probation Service (HMPPS). Jason joined HMPPS Interventions Services in 2010, where he has worked on developing, evaluating and quality assuring Offending Behaviour Programmes. More recently, he has led a number of collaborations to co-produce digitally-enabled approaches to promoting desistance.
\end{abstract}

Charlotte Gibbs is currently undertaking her professional qualification in probation. Prior to this, she worked as a National Specialist Trainer for 4 years for HMPPS Intervention Services. She has experience of working with people on probation within the field, and as an accredited programme facilitator.

Lara Jonah is a Chartered and Forensic psychologist working for Her Majesty's Prisons and Probation Service, where she is the clinical lead for a Domestic Abuse Interventions.

Dr Sinead Bloomfield is a chartered Research Psychologist in the Research and Evaluation team of Prison and Probation Analytical Services at the Ministry of Justice. Sinead has eighteen years' experience of research in a Forensic setting. Sinead has widely disseminated research for both specialist and generalist audiences. Sinead has extensive experience in the assessment and treatment of domestic violence/intimate partner violence.

Following a career as a criminal and family lawyer, Paul Weatherstone qualified as a Probation Officer in 2001. As the national lead for Violence Interventions at HMPPS, Paul led the team that took the Building Better Relationships programme to accreditation. He also worked as HMPPS policy lead for Domestic Abuse before taking up his current post as Head of North of Tyne National Probation Service.

Professor Jane L Ireland is a Chartered Psychologist, Forensic Psychologist based at the University of Central Lancashire and Ashworth High Secure Hospital, where she leads a forensic clinical research centre. She has worked for over 20 years in forensic practice and specialises in applied forensic research. She continues to work in practice, leading violence treatment therapies.

\footnotetext{
${ }^{1}$ Corresponding Author: Jason.morris@noms.gsi.gov.uk
} 
Developing Content to Promote Desistance in Men Who Have Committed Intimate Partner Violence in Same-Sex Relationships

\begin{abstract}
This paper provides an overview of service development processes used to design a therapeutic approach that promotes desistance amongst men who have committed acts of Intimate Partner Violence (IPV) against their male partner or ex-partner. The article aims to explore how inclusive therapeutic service provision can be developed using the best available evidence, stakeholder consultation, co-production and technology. It does so by presenting a two-part study that draws upon a review of inclusive IPV theory alongside responses to a consultation designed to canvas stakeholder opinions $(n=14)$ of a proposed IPV service. It also provides a case study $(n=1)$ of the co-production of digital media with someone from the target group for that service. Implications for future service design for marginalised groups in the Criminal Justice System and provisions for people who have committed IPV are discussed.
\end{abstract}

This article represents the views of the authors' and not those of Her Majesty's Prisons and Probation Service (HMPPS).

Keywords: IPV; Same-sex relationships; digital media; violence intervention. 
Intimate Partner Violence (IPV) is a public health concern of global significance (WHO, 2005). The Crime Survey for England and Wales (ONS, 2018) shows that in the year ending March 2018 an estimated 2 million ( 1.3 million women, 695,000 men) adults aged 16 to 59 years experienced domestic abuse. It is important to note that prevalence rates are dependent on how IPV is defined and as such figures like these need to be interpreted with care when considering their implications for public policy and identified therapeutic approaches for those with convictions for IPV. Notwithstanding, debate in this area has led some to suggest that the prevailing feminist orthodoxy in the field of IPV has fallen somewhat short of accounting for violence in LGBT relationships (e.g., Potoczniak, et al., 2003) and tends to overlook the potential range of victims of IPV (e.g., Birch \& Veljanova, 2018). This arguably has had a limiting effect on the development and integration of inclusive desistance-orientated IPV approaches for those who identify as LGBT.

Burke, et al. (2002) found the prevalence of IPV amongst LGBT couples was approximately $25 \%$ to $50 \%$. In a later UK study of 1,911 lesbians and 1,391 gay men, $22 \%$ and $29 \%$ respectively self-reported physical, sexual or mental abuse or violence from any regular sexual partner (Henderson, 2003). Similarly, more recently, Finneran \& Stephenson (2013)'s systematic review found that (whilst data on perpetration rates were scant) rates of self-reported experiences of IPV victimisation were equivalent (or higher) amongst men who had sex with men in comparison to rates documented among women. Thus, violence in same-sex relationships is worthy of both academic and policy attention.

Research exploring risk factors underpinning the perpetration of IPV amongst those who identify as LGBT is limited. A variety of reasons have been put forward to explain this, including: the marginalisation of LGBT issues, denial of a problem within LGBT communities (fuelled by a fear of triggering homophobic responses) and a lack of attention from statutory and criminal justice agencies (Toro-Alfonso \& Rodriguez-Madera, 2004). 
Similar to studies involving heterosexual IPV (e.g., Gilchrist, et al., 2003), LGBT IPV has been associated with the use of coercion; experience of jealousy; and, use of dishonest, isolating, humiliating behaviour towards victims (Merrill, 1998); conflict resolution and attachment (Stanley, et al., 2006); and, stress, anger, alcohol use, and alcohol-related problems (Lewis, et al. 2016). This equivalence in the forms of IPV within heterosexual and same-sex relationships is also supported by Frankland \& Brown (2014), who identified that patterns of IPV in LGBT relationships were consistent with those originally identified in heterosexual couples. A central factor underpinning these patterns was the use of coercive and controlling behaviours.

Merrill (1998) emphasised that key determinants of IPV were independent of sexual orientation, namely: growing up learning how to be violent (influenced by instruction, modelling and reward); having opportunity to be violent (which can be created via power and isolation); and, choosing to be violent (a decision that is influenced by substance abuse and a range of psychological variables, such as communication/social skills, impulse control and attitudes towards relationships and violence).

Similarities between the underpinning drivers of IPV across different gender identities and sexual orientations have led the authors of the Spousal Assault Risk Assessment - Version 3 (SARAV3; Kropp \& Hart, 2015) to suggest that their tool is appropriate for all people who use IPV, regardless of gender. Whilst the SARA manual refers to perpetrators of IPV as "he" or "him" and to victims of IPV as "she" or "her", they acknowledge that "for all intents and purposes, she or her may be read in place of he or him, and vice versa, without changing the meaning of the text". (pp. 1).

This allows for the possibility for IPV to be perpetrated by women or indeed within same-sex relationships involving either gender. It also suggests that the factors within the SARA can be considered to apply to either sex or any sexual orientation. Notwithstanding, the literature identifies many nuances that can characterise acts of IPV that fall outside of the heterocentric 
"public story" of IPV (see Donovan \& Hester (2010) for a discussion of this "public story"). Understanding and reflecting on these features offers an opportunity for services to be responsive to LGBT participants to help them self-manage their relationship behaviour.

Some features that may require additional consideration for same-sex relationships reflect the interplay between victim and perpetrator. An emerging field of study of relevance here is Sexual Minority Stress. This has been defined as "a multifaceted construct that includes experiences specifically related to one's sexual minority status" (Lewis, et al., 2012, p. 251). Externalised minority stressors include general sexual-orientation-related victimisation and the perception of prejudice or discrimination. Internalised minority stressors include identity concealment and internalised homonegativity, which are discussed below.

Burke, et al. (2002) reported that LGBT IPV perpetrators sometimes exploited the identity concealment of victims by using the threat of "outing" them. Perpetrators may control how a partner expresses their sexuality, due to the perpetrator's desire to conceal their own sexual orientation. It has also been noted that discrimination and biases may protect abusers from the negative consequences of their behaviour by making victims less likely to seek help from the police or other support services (e.g., Lundy, 1993). Despite progress within the ability of mainstream services to prevent and respond to IPV in LGBT relationships, the understandable reluctance of some LGBT IPV victims to seek support may be a factor that aggressors consciously or unconsciously exploit to sustain their IPV.

Internalised homonegativity is a form of Sexual Minority Stress, which can be associated with self-hate or low self-esteem (Byrne, 1996) and with the perpetration of IPV (Bartholomew, et al., 2008; Edwards \& Sylaska, 2013). Internalised homonegativity can be present in the perpetrator who projects their negative self-concept through IPV (e.g., through homonegative insults), and with the victim, who may see themselves as deserving of such treatment as a result of their sexual orientation (Balsam, 2001). 
Lewis, et al. (2012) suggested that those who self-identify as LGBT may attempt to cope with minority stress through substance use, a known risk factor in IPV. It is also important to consider that whilst those who identify as LGBT may experience relationship difficulties linked to minority stress (including internalised homonegativity), many do not. As such it is important for services to enable participants to describe their own unique pathway into IPV and to focus their efforts to desist on the issues that are most relevant to them.

Andrews \& Bonta (2010) highlighted that an appreciation for a person's social and cultural background enabled practitioners to work with them responsively. In the context of IPV, the Nested Ecological Model (NEM: Dutton, 1988, 1995) provides practitioners with a useful theoretical framework to define, describe, and illustrate how intersectional influences such as racism, classism, sexism, misogyny, homonegativity and transphobia can be internalised and contribute to IPV (also see Cannon, et al., 2015). Dutton (1995) argued that layers of social influences, and interactions between these layers, influence attitudes and behaviours that lead to IPV. He also highlighted that society's response to IPV can be adjusted to meet the challenges associated with different layers. The layers of influence described in the Nested Ecological Model include the broader culture (macrosystem), subculture (exosystem), family (microsystem) and individual characteristics (ontogemy) (Dutton, 1995). Features from broader culture (such as living in a patriarchal, homophobic society) can have a significant impact on individual learning history by diminishing the influence of protecting factors and strengthening "moderating variables" in the exosystem and microsystem.

The General Aggression Model (GAM: Anderson \& Bushman, 2002) is worth considering since it provides a bio-socio-cognitive framework, broadly compatible with Dutton's Nested Ecological Model, which helps to gain a clearer picture of how cultural and societal influences can impact on the decision-making that runs alongside the perpetration of IPV. The General Aggression Model presupposes that biological factors (such as sex) and societal factors (such as 
patriarchy and homonegativity) impact on a person's developmental history, which then influences internal states and decision-making that results in a use of aggression (in this instance IPV) in specific situations. DeWall, et al. (2011) indicated that there are dozens, if not hundreds, of "person" factors (rooted in the individual's developmental history) involved in IPV including trait anger, attachment style, alcohol abuse and beliefs. Some of these factors will reflect psychological states and traits identified in meta-analyses (e.g., Archer, 2000) to be empirically linked to IPV in groups of people, whilst some of these factors may be idiosyncratic (and relevant to a specific person's pathway into using IPV). All can be captured by multifaceted models of behaviour like GAM, which can be applied within desistanceorientated courses to aid understanding of behaviours such as IPV (e.g., Ireland \& Ireland, 2018; Walton, et al., 2017).

The GAM can be used as a framework to help any individual understand their pathway into IPV by enabling them to consider how their personal attributes (i.e., sex, personality and intersectional identities) may predispose them to IPV when triggered by certain situational factors. Recognising that personal attributes sometimes stem from traumatic experiences from an individual's learning history can enable practitioners to help participants explore relevant cognitive, emotional, physical, and behavioural symptoms of trauma within the context of a safe and supportive working relationship (Leitch, 2017). These values are consistent with strengthsbased desistance-orientated approaches, which aim to enable participants to form meaningful therapeutic relationships with practitioners (see Ross, et al., 2008); identify and build on strengths (McNeil, 2012); and, develop skills that allow them to lead a better life (Looman \& Abracen, 2013).

GAM can also be operationalised via a "self-monitoring process" that enables participants to log thoughts, feeling and behaviour to help them deconstruct their episodes of aggression (NB - it is not necessary to refer explicitly to "GAM" with participants). This provides a platform for them to understand patterns in their behaviour (including coercive control) and strengthen 
their ability to identify thoughtful, nonaggressive alternative responses. Furthermore, Allen \& Anderson (2017) argued that the "episodic, learning trial approach" provided by GAM "can be used to explain the development of nonaggressive or prosocial personalities" (pp. 690). They argued that GAM could be used to understand how repeated exposure to prosocial messages can promote rehearsal, and reinforcement of prosocial knowledge structures that promote desistance. This highlights the potential of self-monitoring as a method to record and reinforce positive behaviours and strategies and thereby promote desistance in people with IPV convictions.

In England and Wales, the principal accredited Offending Behaviour Programme (OBP) for people with IPV convictions (Building Better Relationships; BBR) conceptualises IPV using GAM. BBR involves around 64 hours of mainly group participation. Much of the content of BBR was derived from two previous programmes: the Integrated Domestic Abuse Programme (IDAP) and the Community Domestic Violence Programme (CDVP). IDAP and CDVP have been shown to have a positive impact on participants in terms of reducing reoffending (Bloomfield \& Dixon, 2015). It is the contention of this paper that framing IPV within a gender non-specific, multifaceted model of behaviour enables courses like BBR to provide an appropriate basis for adapted provision for people who have hitherto been excluded due to their gender or sexuality.

Exploring the theoretical appropriateness of themes that run through BBR - like GAM (Anderson \& Bushman, 2002); NEM (Dutton, 1988); and, strengths-based working (McNeil, 2012) - for people who have committed same-sex IPV is important from a practical, service delivery perspective. A significant issue in the field of same-sex IPV is whether there is enough actual demand of convicted individuals to enable a sustainable approach to promoting desistance. It does not necessarily follow that self-reported rates of same-sex IPV (e.g., Burke, et al., 2002) translate into charges and sentences. Indeed, a European survey of perpetrator interventions (Hamilton, et al., 2013) did not report on any same-sex IPV interventions. It is our contention 
that reasonable adjustments to existing infrastructure and expertise rolled out nationally via BBR represents an opportunity to enable sustainable provision for people who have committed IPV is same sex relationships.

In the context of desistance-orientated approaches, Maruna (2001) emphasised the importance of "wounded healers" who draw on their own experiences to assist their peers to recognise their own skills and learn from their mistakes. One means of drawing on these types of experiences may be via the Complementary Digital Media (CDM) approach² (Morris \& Knight, 2018). This approach has been used to capture the stories and voices of male prisoners within brief animated media clips. These clips involved basic skills modelling examples to provide users with a clearer idea of what successful coping might look like. In their role as peer supporters, the co-creators of CDM assisted prisoners to access these clips (via in-cell computers) and to discuss how they could integrate such skills in their own day-to-day life (see Morris \& Knight, 2018). Morris \& Knight (2018) described the potential for CDM to complement conventional OBPs by using clips during existing face-to-face sessions and by making them available to participants outside of sessions to consolidate learning.

The current paper aims to draw together these areas of research and practice. The nascent but modest research literature around LGBT perpetration of IPV is considered alongside the CDM approach to developing nuanced rehabilitative OBP content. It does so by reporting on a two-part study key to the development of evidence-informed desistance-orientated content for men who have used IPV against a male partner. Focusing on men, Part 1 explores stakeholder responses to a proposed standalone CDM-based LGBT-inclusive course (developed under the name of "Spectrum"). Part 2 describes an application of the CDM co-production framework (Morris \& Knight, 2018) to develop desistance-orientated content designed to be responsive to men who have used IPV against a male partner. No specific predications were made within the two-part

\footnotetext{
${ }^{2}$ An explanation of CDM can be found here: https://youtu.be/QFWBnUYTvMk
} 
study. Rather, the study was driven by two core aims, to: 1 . capture stakeholder perspectives on the therapeutic application of specific techniques (such as self-monitoring, skills building and the strengths-based approaches) for the LGBT community who have been involved in IPV perpetration; and, 2. explore service user experiences in co-producing desistance-orientated course content. The paper discusses the implications of using this content in a variety of therapeutic services in order to adopt a fully inclusive approach to promoting desistance in individuals who have perpetrated IPV.

Part 1: Stakeholder Views of an Outline Framework for Providing Desistance Orientated Support including of LGBT perpetrators of IPV

Participants and method

A briefing document was produced to establish stakeholder views on a proposed OBP approach to meet the needs of participants whose offending fell outside of the "public story" of IPV. The briefing document outlined a cognitive behavioural course based on a multifaceted understanding of IPV and desistance-promoting practices (e.g., strengths-based approaches). The approach consisted of 10 face-to-face sessions delivered flexibly to LGBT or Heterosexual female participants on a one-to-one basis. The approach was intended to be offered as a standalone programme to participants deemed 'low' risk (for example, to help fulfil a Rehabilitation Activity Requirement in the community). The briefing document provided the basis for a consultation, undertaken in spring of 2016, which asked for stakeholders (i.e., groups and individuals likely to have an interest this area) to consider the following questions:

1. Would they advocate one-to-one or group approach?

2. What did they think about using the General Aggression Model to understand IPV?

3. What was an appropriate length and number of sessions? 
4. Which staff should deliver the approach (e.g., accredited programme facilitators or responsible officers)?

5. What level of quality assurance and supervision would be appropriate to support the approach?

6. Would their group/section/team endorse the new service?

7. What other advice did they have around design, content and/or targeting?

The briefing document was distributed amongst a range of relevant stakeholders. This included groups within HMPPS, Community Rehabilitation Companies (CRCs), academics with an IPV interest and specialist LGBT charities/community groups. Stakeholders who wished to receive more information were provided with further detail of the proposed approach. In total 55 copies of the consultation document were forwarded to organisations and individuals. 14 completed responses were received; eight representing the views of CRCs, one representing a LGBT charity, three from sub-groups within HMPPS and two from academics who have published research relating to LGBT IPV.

\section{Results}

There were mixed views amongst respondents on how to achieve better provision in this area. Contributions that reflected endorsement of the approach proposed in the consultation included [participant number]:

Yes if resources allowed [P1]

I think it is necessary. The HO definition which we sign up to is an inclusive one and just because we don't have big numbers doesn't mean that we shouldn't do anything [P49] 
No specific intervention available for IPV LGBT offenders. May be a valuable additional resource. [P30]

Welcome addition to the suite of interventions that are currently available [P30]

Our programmes team would fully endorse [P32]

We run ... a 10 session programme devised by the University ... something less repetitive would be preferable to staff if they were to engage with the new programme [P47]

Several respondents recognised the potential to expose LGBT participants to isolation and discrimination if they were placed on an existing group comprised of heterosexual male participants. One respondent, however, highlighted the perspective that existing provision should not arbitrarily exclude men who have been violent towards a male partner:

Men should be given a choice and make an informed decision [about attending BBRJ.....I appreciate there are other issues but if a man said "I accept the risks and all I ask of you as facilitators is to manage the group" then should he not be on group if he needs it? [P49]

There were some reservations about whether the bio-psycho-social and strengths-based approaches from BBR were sufficient to address the needs of LGBT participants.

The issues of motivation for heterosexual female, lesbians, gay males and both sexes of transgender participants are likely to be different and will need to be addressed in different ways [P23]. 
I would like to see the research that states that there are enough similarities between abusive relationships across genders and sexuality in order to adapt BBR materials [P55].

Several respondents also indicated a view that patriarchy should have a presiding role in all efforts to understand and address IPV:

Domestic abuse is often a pattern of behaviour that is developed through the lens of male privilege. I am not saying this accounts for all abuse but it cannot be ignored [P55]

It is crucial to recognise the role of gender within domestic abuse. This underpins the sexism, homonegativity, biphobia and transphobia commonly used by perpetrators and which provide barriers to seeking support [P42]

Patriarchal ideas affect all of us regardless of our sexuality and gender identities and infuses our understandings of intimate relationships so that we expect binary behaviour [P50]

Other respondents were comfortable with the gender non-specific approach of the General Aggression Model and the use of strengths-based methods:

Yes to GAM and NEM - found to work well with male perpetrators of IPV in heterosexual relationships - most appropriate and suitable as it does not apply the "patriarchy model" therefore makes it inclusive to the target group [P32]

Responses from providers recognised that whilst there was a need for provision for LGBT IPV participants, some questioned whether the need was sufficiently large to justify the resources 
required to meet it. Notwithstanding, one CRC reported having already begun to create provision that "could be specifically targeted at this cohort". There was generally strong support that the approach should be one-to-one. This was summarised by an LGBT charity in their response:

The rationale for a one-to-one programme is three-fold: diversity amongst LGBT people suggests a group work intervention for LGBT people might be counterproductive; insufficient need for group work would prevent this from being viable; the economics of providing group work for each sub-group (a lesbian group) or even for women/female and men/male-only groups also mitigates against this approach. One to one is both theoretically and economically justified at this point [P50]

Whilst the proposed length of sessions (90 minutes) was generally seen as acceptable for a one-toone approach, some respondents argued for a longer intervention than 10 sessions. Most of the respondents who remarked on staffing suggested that the use of existing BBR facilitators would be an effective way of ensuring quality of delivery of sessions. There was also recognition that probation practitioners responsible for managing individual cases could be a useful resource for delivering the approach (e.g., as a flexible toolkit) if they could be adequately supported. The specific advantages of this were that Responsible Officers would already have a relationship with the participant and they could build delivery into their routine supervision sessions.

Respondents who commented on suggested supervision arrangements for the proposed approach agreed that a local supervisor should have overall clinical responsibility at each delivery site. There was also support for the idea that the approach made use of the Partner Link Worker (PLW) ${ }^{3}$ process, which is employed within the BBR programme.

\footnotetext{
${ }^{3}$ PLWs work with victims and current partners of men attending domestic abuse programmes to promote the safety of women and children.
} 
Respondents reported that being responsive to LGBT IPV participants was a nuanced task, which required a conscientious and informed approach. One respondent indicated some of the likely challenges associated with this work and how it should be pitched to help LGBT participants feel supported:

Focus on an individual's sexuality/gender identity is not always appropriate and is something they are wary of practitioners doing, i.e. they are wary of their sexuality/gender identity becoming problematized. On the other hand, for those who have only recently come out and/or do not have much experience of being LGBT they might benefit from opportunities to reflect on their identity especially in relation to intimate relationships. [P50]

The consultation also suggested that the approach should be opened out to include women in samesex or mixed-sex relationships. A number of respondents suggested that more than two days of training would be required to ensure that existing BBR facilitators were sufficiently equipped with the knowledge and skills to be responsive to female participants:

It would likely benefit the training participants to attend training for longer than two days. Our standard LGBT domestic abuse training, delivered to domestic abuse support staff, is best delivered over 1.5 days in order to fully cover LGBT domestic abuse dynamics and support needs. Adding the dynamics of abuse perpetrated by a woman within mixed-sex relationship may require longer than the remaining half day. We strongly suggest that the programme be delivered by staff already skilled in the existing model [BBR]. [P42] 
Several respondents queried the rationale for the inclusion of heterosexual women and LGBT participants within the same target population and indeed with the very notion of intervening with women as perpetrators of IPV.

Part 2: Case Study of Co-Producing Complementary Digital Media for a Desistance Orientated Approach for Men with IPV Offences Against Male Partners

Participant and method

Following the consultation, a large community probation provider (Reducing Reoffending Partnership; RRP) approached the first author's group (HMPPS Interventions Services) wishing to collaborate on the development of a desistance-orientated approach like the one proposed in the consultation (with the additional inclusion of heterosexual males). A steering group was established to plan the co-production of a service that would build on findings from Part 1.

The service ${ }^{4}$ would consist of 10 sessions. Each session would involve up to three separate rehabilitative conversations. The steering group agreed that the service would be designed in line with the CDM approach described by Morris \& Knight (2018). Co-created CDM clips would provide an agenda for each rehabilitative conversation. CDM clips would typically: present a central character experiencing a challenge; introduce a skill; and, present the character using the skill to resolve the challenge. Supporters would use clips flexibly during sessions (e.g., pausing, replaying, etc); generate discussion to elicit the personal relevance of content; and, facilitate tasks to generalise learning (e.g., skills practices and worksheets). Parallel variants would be coproduced to reflect either heterosexual or same-sex relationship content. The heterosexual male variant would be delivered as a group. The same-sex male variant would be delivered on a one-to-

\footnotetext{
${ }^{4} \mathrm{~A}$ clip that advertises the pilot service is depicted here https://youtu.be/cv7J511e3Eo
} 
one basis or in small groups (depending on demand). Wherever possible, delivery teams would ensure that BBR facilitators were involved in delivering and/or supervising sessions.

In line with the approach set out be Morris \& Knight (2018), CDM content would be co-produced in a focus group (called a Service User Reference Group; SURG). To recruit volunteers, RRP staff promoted the co-production project amongst service users. The SURG met on at least a fortnightly basis over a nine-month period.

The current paper focuses on the co-production of the male same-sex variant of this initiative. Weaver (2013) described the process of "co-producing desistance" in individual, group or community forms. Whilst we had originally intended to involve a group of gay or bisexual male service users, low numbers hindered the recruitment (a limitation discussed below). In this section, therefore, we describe a form of individual (rather than group) co-production, which involved one gay male $(\mathrm{N}=1)$ referred to throughout as "Colin". Colin was serving a community sentence for IPV against a male partner. Towards the end of the project, Colin also obtained the protection of a restraining order for IPV offences perpetrated against him. As part of the co-production project, Colin consented to participating in following activities:

- Creating ideas for digital content: identifying topics, skills and scenarios relevant to the aims of the service being developed. This involved developing storyboards and scripts that model the use of skills in relatable situations.

- Recording voice-overs.

- Providing feedback on the digital media and how it could be used therapeutically.

Colin co-produced scripts and provided voiceovers for sixteen animated clips for the male same sex variant of the approach. These CDM clips depicted a central character in various IPV-related scenarios where he often used skills drawn from BBR to self-manage. For example, he created and voiced scenarios to help model the self-monitoring process (see Figure 
1) and different types of "OK and Not-OK" relationship behaviour. He also co-created scripts to model positive coping and skills in situations that he would find risky.

[Figure 1 here]

Presented next are Colin's responses during an interview conducted by one of the authors (CG) to further explore his experiences of the co-production process.

Results

In Colin's words, the purpose of the project was: "to make people realise that gay, straight, whatever you are, we are all the same" and that "everyone is equal, we are all human". In describing his role within the co-production process, he explained that:

I made up a character called CAM, who was based on bits of my life from experiences I've received from a child to now. Made videos with [JM] and ... I don't know what to say-it's more about learning about myself and creating a person that isn't me, but kind of is me because of his experiences.

He described that his purpose in the project was to share his experiences of using IPV: "bring those experiences into this room and put them into scenarios to help other people in the future".

Colin acknowledged experiencing anxiety prior to attending SURG sessions:

That was me, panicking just because I'm gay. And it's like, you don't know who is going to judge you because some people are quite iffy about it.... It still isn't as normal as being straight. That's what scared me. 
Before I felt like shit and after I felt better. I thought, yeah I'm doing wrong but I'm also doing right. I was getting it mixed up and confused.

Colin engaged collaboratively with staff to ensure that CAM's pathway into using IPV could be depicted through a series of clips that the target group would relate to:

Listening and speaking... [CG] saying, "how would you feel in that scenario" and [JM] listening and saying "how would you feel about if I put this?" for the script for the video. And I'd think, yeah, but if it was wrong, I'd say '[JM], no change that because I wouldn't say that, I would say 'you gay faggot' or something - even though being gay myself - but that would be what I said to hurt that person at the time ...I wouldn't say "you twat", I'd say “you dirty gay-boy faggot” - just to hurt him. It's stupid because I'm gay myself, but I'd want to hurt him for being gay as well. It's sounds ridiculous, but it is what you do when you are in that moment. ...... I'd thought about the situation I was in and put it in my words instead of an actor's

It was evident that the SURG sessions were having a positive impact on Colin and that he had derived some meaning from his involvement:

I showed my ex-[name], who is now my really good friend. I showed him the videos that [JM] sent on email. He said "I'm so proud of what you've done, [Colin]". Because we had difficulties in our relationship. He wasn't upset, but I could see it in his eyes. I'm actually doing something with my life, I'm getting to know myself again and not being the person he thought I was when we were together...... to hear it from an ex, who you have been in love with and you have had to leave for personal reasons, and to hear him say "I'm proud of you", it's nice to hear....it does give you that buzz, and it makes you believe in yourself. 
It was evident that during the time he was attending sessions, Colin was living within destabilising personal circumstances:

I'll come in and I'll rant and rave-about what's happened. ...... you have to get it all out to carry on with these sessions before you do the talking into the microphone. If you don't get it all out, I'm going to end up in tears, stressed, and I'm going to walk out.

It appears that Colin experienced personal support as a result of being part of the co-production process:

For me it is being able to talk things through with people who aren 't part of my life. I'd come to you, and chat so much shit about what is going on, and it's gone. I don't need to go to my mate up the road and say it all again.... You two don't have an opinion, you don't come back with an opinion. You say, 'this is your choice'. You said to me a couple of weeks ago, 'the only person who can change your choices is yourself'. What have I done? I've managed to get [my ex] out of my life, restraining order the lot. ... it's good.

When asked what would be the best way to develop digital content in the future, Colin indicated that he would recommend the same process to ensure that the material was relatable: "you can't get any more than real life. Real life is real life. You can't make it up".

It was evident that Colin was aware of the importance of his contributions and he derived some satisfaction from his opportunity to give something back in a way that few others could:

If it wasn't for us, you would have nothing, and I don't mean that in a rude way, I'm saying it blatantly. If it wasn't for me - and everybody else - you would have nothing. 
We have aimed to capture and celebrate Colin's contributions to this project via a CDM clip which presents his story alongside a volunteer contributing to the heterosexual male variant of the programme ${ }^{5}$.

\section{Discussion}

The research demonstrated that conflicting positions exist in the views of stakeholders interested in the conceptualisation of IPV and addressing the needs of those who perpetrated it. The proposed use of the General Aggression Model (GAM; Anderson \& Bushman, 2002) as a basis for understanding IPV appeared to polarise stakeholders. Some had direct experiences of using this model within an existing IPV programme (namely BBR), and consequently supported its proposed use. Some, however, suggested that the focus on aggression was distinct from (and therefore not inclusive of) coercive and controlling behaviours. It was important therefore that the proposed approach articulated clearly how coercive control could be understood within a GAM-based self-monitoring process (see Figure 1 for an example).

During the consultation, several respondents felt strongly that rehabilitative approaches to addressing IPV should emphasise that the inter-related factors of gender and patriarchy are key to all forms of IPV. The approach proposed in the consultation framed gender and patriarchy within the multifaceted General Aggression Model alongside a wide range of other factors relevant to the participant's unique offence pathway (as does BBR). Acknowledging a varied and multifaceted blend of contributing factors was in keeping with research (e.g. Gilchrist, et al., 2003; Stanley, et al., 2006) although this was recognised only by those respondents who had already had some previous exposure to the GAM.

\footnotetext{
${ }^{5} \mathrm{CDM}$ clip to capture the experiences of creating "CAM" https://youtu.be/cv7J5/1e3Eo
} 
As indicated in Part 1, the development of IPV provision for women is a contentious subject.

Conflicting viewpoints within HMPPS about how IPV committed by women should be conceptualised have curtailed efforts to co-create new variants of the strengths-based, traumainformed approach (described above) that is currently being piloted with males. The authors invite further discussion on the appropriateness of therapeutic IPV provision that does not exclude females.

The content co-produced with the volunteer from Part 2 of the study was designed to help OBP participants develop insight into and to self-manage IPV behaviours (inclusive of coercive control). Figure 1, for example, depicts the use of the GAM-based self-monitoring process to unpick a co-created scenario of coercive and controlling behaviours including threats and putdowns. Through this process, such acts of IPV can be understood as the product of interactions between situational and enduring personality factors (e.g., Graham-Kevan \& Archer, 2005). Basing the depiction of these issues on the lived experiences of someone convicted of IPV, enabled social factors in CAM's learning history to be presented. It was evident in Colin's contributions to the project that such factors (e.g., heterosexism, patriarchal norms, homonegativity, childhood trauma, etc) had all filtered through Colin's learning history. It was evident that the co-production process prompted Colin to reflect constructively on his own psychosocial development and relationship behaviour (e.g., "I'm getting to know myself again and not being the person he thought I was").

Reminiscent of the findings of Balsam (2001), who stipulated that internalised homonegativity could propagate IPV through its effects on both victim and perpetrator, the research hints at complex dynamics and impacts of sexual minority stress within LGBT IPV. The sexualorientation-related victimisation used by CAM in his IPV had the potential to portray the heightened sexual minority stress experienced by his victim. Colin's disclosures also evidence a degree of projection in the homonegative insults that he directed towards his partner (see quote: "I would say 'you gay faggot' or something ....I'd want to hurt him for being gay as well”). This 
is speculative but it does identify again the importance of considering LGBT IPV as an interaction with a range of dynamics and impacts.

Sexual minority stress also presented as a factor that impacted on Colin's experience of the coproduction process itself. Within his disclosures, he acknowledged that choosing to engage with the project had been difficult because he expected people to react negatively sexual orientation (e.g., "you don't know who is going to judge you because some people are quite iffy about it.... It still isn’t as normal as being straight. That's what scared me").

Whilst Colin experienced stress during the co-production process (e.g., "panicking just because I'm gay"), he also reported a range of positive consequences to his involvement. A number of his disclosures appeared to be consistent with Maruna (2001)'s perspectives on desistance. For example, it is arguably evident that he experienced social inclusion through his collaboration with staff involved in the project (i.e. "I'd come to you, and chat so much shit about what is going on, and [then] it's gone") as well as through him sharing the end products of his involvement with people in his support network (i.e. "he said 'I'm so proud of what you've done, C'.') Maruna (2001)'s desistance perspective of 'healthy self-narrative' is implied by responses such as "I'm actually doing something with my life .... it makes you believe in yourself". Finally, it was incumbent on SURG staff to provide impartial pastoral support to help Colin engage with SURG tasks against the backdrop of his destabilising lifestyle circumstances. The participant's response to the "strategy of choices" approach adopted by the staff (see Bush, Harris \& Parker, 2016) appears to reflect Maruna (2001)'s desistance perspective of maturation (e.g., "You two don't have an opinion, you don't come back with an opinion. You say 'this is your choice'. You said to me a couple of weeks ago, 'the only person who can change your choices is yourself,.").

Colin's contributions during the co-production of CDM and his disclosures in the research provide a voice of lived experience that embodied a range of factors within the literature 
associated with LGBT IPV (see Merrill, 1998; Stanley, et al., 2006; Byrne, 1996;

Bartholomew, et al., 2008; Miller, et al., 2000) and desistance-orientated approaches (McNeil, 2012; Looman \& Abracen, 2013; Maruna, 2001). Further research with participants of the new service will help determine whether the synthesis of these ideas in the character of CAM is relatable for participants. This research will also capture the reactions of future participants to broader aspects of the content and delivery model of the piloted approach.

The research presented here highlighted the importance of addressing the uniqueness of participants and appreciating the intersectional influences on their individual pathways into using IPV. We aimed to capture these influences in the case example of "CAM", which is now available to facilitators aiming to help participants to self-manage factors contributing to their perpetration of IPV. The approach is consistent with stakeholder sentiments around the relevance of gender and patriarchy, albeit without placing these factors at the heart of the service.

There are undoubtedly limitations that need to be recognised in the research. The low response rate of stakeholders (in Part 1) and small uptake of volunteers (in Part 2) impacts on the generalisability of the findings. Whilst approaching a higher number of stakeholders for Part 1 would likely have resulted in a wider spread of contributions, there was a particularly rich and engaged set of responses. Several community groups and academics provided apologies for their inability to respond on account of prevailing workloads. Whilst only one volunteer was recruited to Part 2, this can be understood in the context of the barriers to engagement faced by people in the target group. The reliance on single volunteer is also likely to have promoted ownership and in-depth involvement. The paper presents a preliminary approach to engaging stakeholders and developing OBP content, with the value not just in the findings but how these were reached with regards to the methods adopted and how these could be advanced in future work. 
In conclusion, many aspects of the approach proposed in this paper have been endorsed by stakeholders who generally approved of a flexible one-to-one approach delivered by facilitators who were sufficiently trained and supported to provide a culturally appropriate service to participants who have perpetrated IPV in a context that falls outside of the heteronormative "public story" of IPV. The central role for the General Aggression Model to assist with the conceptualisation of IPV, however, continues to divide opinion, even in the context of LGBT IPV where the relevance of gendered, feminist explanations are less obvious. Factors like gender, patriarchy and sexual minority stress may be relevant factors to an individual's pathway to using IPV, and the multifaceted GAM encompasses these psycho-social factors alongside a range of further factors to help participants develop self-knowledge. We argue that co-production methods enable best practice from extant programme provision to be flavoured by the voices of service users belonging to target audiences. These voices may therefore be important to making therapeutic services responsive to marginalised groups in the criminal justice system. Whilst the principal purpose for enshrining service user stories and voices in CDM is to help participants and practitioners to connect with clear, relatable rehabilitative messages, service developers and providers would also do well to accommodate such voices at a theoretical and strategic level. Indeed our rationale for co-producing culturally-appropriate $\mathrm{CDM}$ to adapt mainstream $\mathrm{OBP}$ content with and for marginalised people is mirrored by Colin's self-disclosed purpose for getting involved in the process; namely to show people that "gay, straight, whatever you are, we are all the same..... everyone is equal, we are all human".

\section{References}

Allen, J. J., \& Anderson, C. A. (2017). General Aggression Model. In P. Roessler, C. A. Hoffner, \& L. van Zoonen (Eds.) International Encyclopaedia of Media Effects. London: Wiley-Blackwell.

Anderson, C. A., \& Bushman, B. J. (2002). Human aggression. Annual Review of Psychology, 53, $27-51$. 
Andrews, D. A., \& Bonta, J. (2010). The psychology of criminal conduct (5th ed.). New Providence, NJ: Lexis Nexis Matthew Bender.

Archer, J. (2000). 'Sex differences in aggression between heterosexual partners: a meta-analytic review'. Psychological bulletin, 126(5), $651-680$.

Balsam, K. F. (2001). Nowhere to hide: Lesbian battering, homophobia, and minority stress. Women and Therapy, 23(3), 25-37.

Bartholomew, K., Regan, K. V. Oram, D., \& White, M. A. (2008) Correlates of Partner Abuse in Male Same-Sex Relationships. Violence and Victims, 23(3), 344 -360. DOI: 10.1891/08866708.23.3.344

Birch, P. \& Veljanova, I. (2018) Raising awareness, improving victim safety: Exploring the efficacy of DFV proactive prevention measures. In J. L. Ireland, P. Birch, \& C. A. Ireland (eds.) International Handbook on Aggression: Current issues and perspectives, London: Routledge.

Bloomfield, S. \& Dixon, L. (2015). An Outcome Evaluation of the Integrated Domestic Abuse Programme (IDAP) and the Community Domestic Violence Programme (CDVP). Retrieved October 6, 2018, from:

https://assets.publishing.service.gov.uk/government/uploads/system/uploads/attachment_data/file 1449008/outcome-evaluation-idap-cdvp.pdf

Burke, T. W., Jordan, M. L., \& Owen, S. S. (2002). A cross-national comparison of gay and lesbian domestic violence. Journal of Contemporary Criminal Justice, 18(3), 231-256. 
Bush, J., Harris, D. M., \& Parker, R. J. (2016). Cognitive Self Change: How Offenders Experience the World and What We Can Do About It. Chichester: John Wiley \& Sons.

Byrne, D. (1996). Clinical models for the treatment of gay male perpetrators of domestic violence. In C. M. Renzetti \& C. H. Miley (Eds.), Violence in gay and lesbian domestic partnerships (pp. 107-116). New York: Harrington Park Press/Haworth Press

Cannon, C., \& Buttell, F. (2015). Illusion of inclusion: The failure of the gender paradigm to account for intimate partner violence in LGBT relationships. Partner Abuse, 6(1), 65 - 77. http://dx.doi.org/10.1891/1946-6560.6.1.65

DeWall, C. N., Anderson, C. A. \& Bushman, B. J. (2011). The General Aggression Model: Theoretical Extensions to Violence. Psychology of Violence, 1(3), 245-258

Donovan, C. \& Hester, M. (2010) "I Hate the Word "Victim": An Exploration of Recognition of Domestic Violence in Same Sex Relationships, Social Policy and Society, 9(2), 279-290.

Dutton, D. G. (1995). The domestic assault of women: Psychological and criminal justice perspectives (2nd ed.). Vancouver, BC, Canada: University of British Columbia Press.

Edwards, K. M. \& Sylaska, K. M. (2013). The perpetration of intimate partner violence among LGBTQ college youth: The role of minority stress. Journal of Youth and Adolescence, 42(11), $1721-1731$.

Finneran, C. \& Stephenson, R. (2013). Intimate Partner Violence Among Men Who Have Sex With Men. A Systematic Review. Trauma, Violence, \& Abuse, 14(2), 168-185. 
Frankland, A. \& Brown, J. (2014). Coercive Control in same-sex intimate partner violence. Journal of Family Violence, 29(1), 15-22.

Gilchrist, E., Johnson, R., Takriti, R., Weston, S., Beech, A. \& Kebbell, M. (2003). Domestic violence offenders: characteristics and offending related needs. Home Office Findings 217.

Graham-Kevan, N. \& Archer, J. (2005). Investigating three explanations of women's relationship aggression. Psychology of Women Quarterly, 29(3), 270-277.

Hamilton, L., Koehler, J. A., \& Lösel, F. A. (2013). Domestic Violence Perpetrator Programs in Europe, Part I: A survey of Current Practice. International Journal of Offender Therapy and Comparative Criminology, 57(10), 1189-1205.

Henderson, L. (2003) Prevalence of Domestic Violence among Lesbians and Gay Men: Data report to Flame TV. London: Sigma Research.

Ireland, J. L., \& Ireland, C. A., (2018). Therapeutic treatment approaches for violence: Some essential components. In J. L. Ireland, C. A., Ireland, P. Birch, (Eds.), Assessment, Treatment and Management of Violent and Sexual Offenders (pp. 319 - 341), 2nd Edition, Routledge: New York, US.

Kropp, P. R., \& Hart, S. D. (2015). The Spousal Assault Risk Assessment Guide Version 3 (SARAV3). Vancouver, Canada: ProActive ReSolutions Inc.

Lewis, R. J., Millentich, R. J., Kelley, M. L., \& Woody, A. (2012). Minority stress, substance use, and intimate partner violence among sexual minority women. Aggression and Violent Behavior, 17(3), 247-256. doi:10.1016/j.avb.2012.02.004. 
Leitch, L. (2017) Action steps using ACEs and trauma-informed care: A resilience model. Health Justice, 5(5), 1-10.

Lewis, R. J., Mason, T. B., Winstead, B. A., \& Kelley, M. L. (2016). Empirical investigation of a model of sexual-minority specific and general risk factors for intimate partner violence among lesbian women. Psychology of Violence, 7(1), 110 -119.

Looman J., \& Abracen J. (2013). The risk need responsivity model of offender rehabilitation: Is there really a need for a paradigm shift? International Journal of Behavior and Consultation Therapy, 8(3-4), 30-36.

Lundy, S. (1993). Abuse That Dare Not Speak Its Name: Assisting Victims of Lesbian and Gay Domestic Violence in Massachusetts. New England Law Review, 20(2), 273-311.

Maruna, S. (2001). Making good: How ex-convicts reform and rebuild their lives. Washington, DC, US: American Psychological Association.

McNeill, F. (2012). Four forms of 'offender' rehabilitation: Towards an interdisciplinary perspective. Legal and Criminological Psychology, 17(1), 18-36.

Merrill, G. S. (1998). Understanding domestic violence among gay and bisexual men. In R. K. Bergen (Ed.), Issues in intimate violence (pp. 129-141). Thousand Oaks, CA: Sage.

Miller, A. J., Bobner, R. F., \& Zarski, J. J. (2000) Sexual Identity Development: A Base for Work with Same-Sex Couple Partner Abuse. Contemporary Family Therapy, 22(2), 189 - 200. 
Morris, J., \& Knight, V. (2018) Co-Producing Digitally-Enabled Courses that Promote Desistance in Prison and Probation Setting. Journal of Criminological Research, Policy and Practice. 4(4), 269 - 279 https://doi.org/10.1108/JCRPP-072018-0023.

Office for National Statistics (2018) Domestic Abuse in England and Wales: year ending March 2018. Retrieved December 20, 2018, from:

https://www.ons.gov.uk/peoplepopulationandcommunity/crimeandjustice/bulletins/domesticabus einenglandandwales/yearendingmarch2018

Potoczniak, M. J., Murot, J. E., Crosbie-Burnett, M., \& Potoczniak, D. J. (2003). Legal and psychological perspectives on same-sex domestic violence: A multisystemic approach. Journal of Family Psychology, 17(2), 252-259.

Ross, E. C., Polaschek, D. L. L., \& Ward, T. (2008). The therapeutic alliance: A theoretical revision for offender rehabilitation. Aggression and Violent Behavior, 13(6), 462-480.

Stanley, J. L., Bartholomew, K., Taylor, T., Oram, D. \& Landolt, M. (2006). Intimate Violence in Male Same-Sex Relationships. Journal of Family Violence, 21(1), 31-41.

Toro-Alfonso, J., \& Rodríguez-Madera, S. (2004). Domestic violence in Puerto Rican gay male couples: perceived prevalence, intergenerational violence, addictive behaviors, and conflict resolution skills. Journal of Interpersonal Violence, 19(6), 639-54.

Walton, J. S., Ramsay, L., Cunningham, C. \& Henfrey, S. (2017). New directions: integrating a biopsychosocial approach in the design and delivery of programs for high risk services users in 
Her Majesty's Prison and Probation Service. Advancing Corrections: Journal of the International Corrections and Prison Association, 3, 21-47.

Weaver, B (2013) Co-producing desistance: Who works to support desistance. In I. Durnescu, F. McNeill, (eds.) Understanding Penal Practice, Frontiers of Criminal Justice (pp. 193-205). Abingdon: Routledge.

World Health Organization. (2005). Violence against women by intimate partners. In WHO multicountry study on women's health and domestic violence against women: Summary report of initial results on prevalence, health outcomes and women's responses. Geneva, Switzerland: World Health Organization.

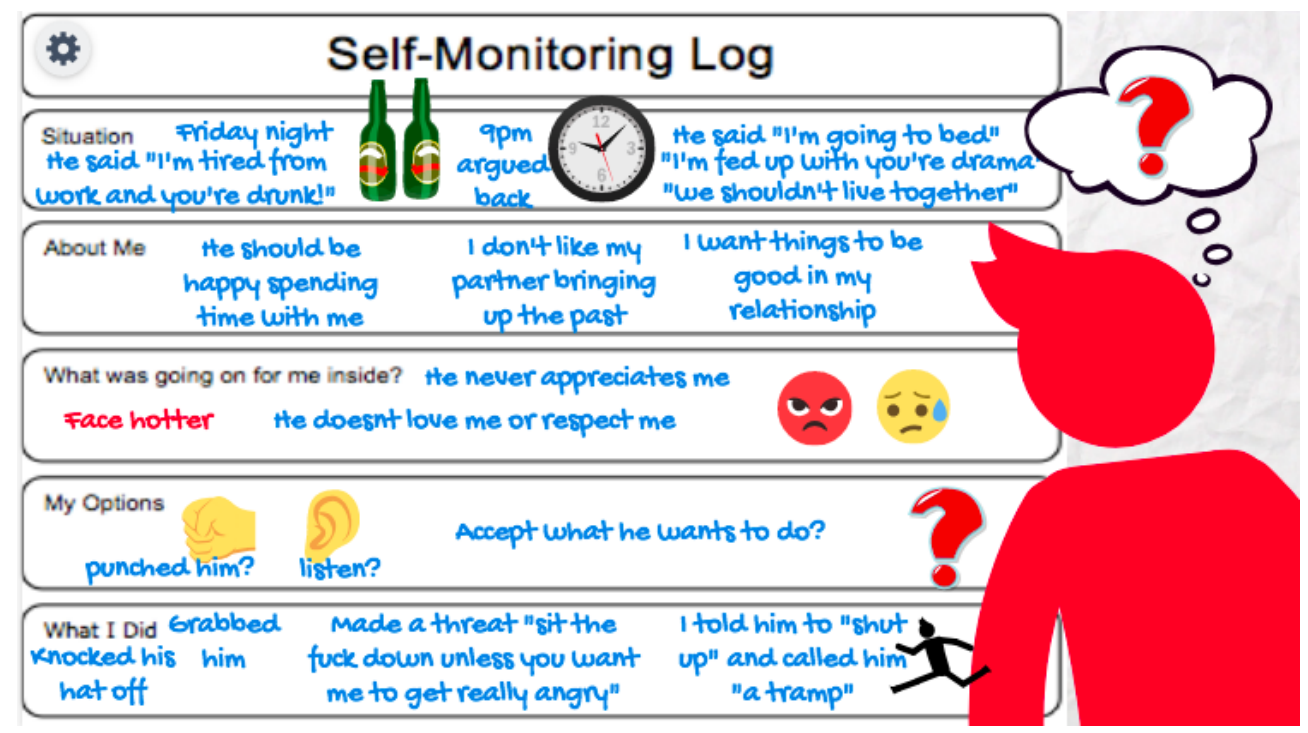

Figure 1: Self-Monitoring Log Used to Capture an Episode of IPV 